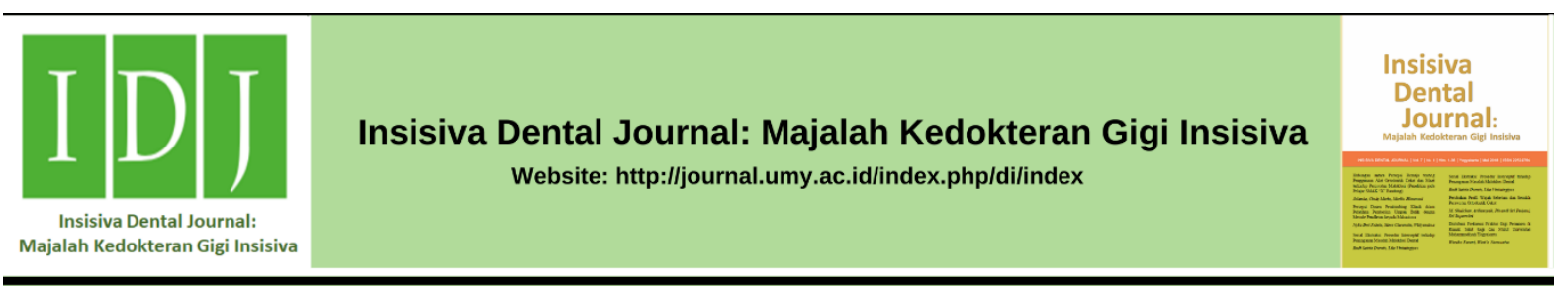

Research Article

\title{
Perbedaan Kekuatan Geser antara Semen Resin Nanosisal Komposit 60\% Wt dan Semen Resin Nanofiller Komposit
}

The Differences of Shear Strength between Composite Nanosisal Resin Cement 60\% Wt and Composite Nanofiller Resin Cement

Dwi Aji Nugroho', Iqban Aditia ${ }^{2, *}$

${ }^{1}$ Departemen Dental Material, Program Studi Kedokteran Gigi, Fakultas Kedokteran dan Ilmu Kesehatan, Universitas Muhammadiyah Yogyakarta, Jalan Brawijaya, Tamantirto, Kasihan, Bantul, Indonesia.

${ }^{2}$ Program Studi Kedokteran Gigi, Fakultas Kedokteran dan Ilmu Kesehatan, Universitas Muhammadiyah Yogyakarta, Jalan Brawijaya, Tamantirto, Kasihan, Bantul, Indonesia.

Received date: November $14^{\text {th }}, 2019$; reviewed date: December $9^{\text {th }}, 2019$ revised date: February $5^{\text {th }}, 2020$; accepted date: March $31^{\text {st }}, 2020$ DOI : $10.18196 /$ di.9112

\begin{abstract}
Abstrak
Resin komposit adalah bahan restorasi yang sering digunakan karena bersifat estetis tinggi. Filler anorganik seperti glass silica sebagai salah satu komposisi penting dalam resin komposit memiliki kelemahan berupa nondegradable, proses energinya tergantung pada bahan bakar fosil, serta emulsi polutannya tinggi dan membahayakan kesehatan dan lingkungan membuat filler alami sebagai bahan pengisi alternatif diperlukan. Salah satu serat alami yang dapat digunakan adalah serat sisal (Agave sisalana). Penelitian ini bertujuan untuk mengetahui perbedaan kekuatan geser antara semen resin komposit nanosisal $60 \% \mathrm{Wt}$ dan semen resin nanofiller komposit. Penelitian ini merupakan penelitian eksperimental laboratoris. Serat sisal selanjutnya diubah menjadi ukuran nano. Nanosisal dicampur dengan Bis-GMA, UDMA, TEGDMA, dan Champhorquinone. Semen resin nanofiller komposit (AllCem Core) sebagai kontrol. Sampel berjumlah 10 dibagi menjadi dua kelompok. Gigi premolar dipreparasi tumpatan kelas V lalu ditumpat menggunakan dua bahan tersebut. Kekuatan geser sampl diuji menggunakan Universal Testing Machine (UTM). Analisis data menggunakan uji Independent Sample TTest. Hasil menunjukkan semen resin nanosisal komposit 60\% memiliki rata-rata kekuatan geser 13,10 MPa, dan semen resin nanofiller komposit 4,92 MPa. Analisis data menunjukkan perbedaan yang signifikan $(\mathrm{p}=0,000)$. Kekuatan geser semen resin nanosisal komposit $60 \%$ lebih besar dibandingkan dengan semen resin nanofiller komposit.
\end{abstract}

Kata Kunci: Nanofiller; Nanosisal; Kekuatan geser; Resin komposit

\begin{abstract}
Composite resin is a restoration material frequently used as it is aesthetically high. Inorganic fillers, such as glass silica as one of the important compositions in composite resins, have disadvantages in the form of non-degradable energy processes that depend on fossil fuels. It is also a high pollutant emulsion that endangers the health and the environment making natural fillers as alternative fillers needed. One of the natural fibers that can be used is sisal fiber (Agave sisalana). This study aims to determine the difference in shear strength between 60\% Wt nanosisal composite resin cement and composite nanofiller resin cement. This research is experimental laboratory research. Sisal fibers are converted to nano size. Nanosisal is mixed with Bis-GMA, UDMA, TEGDMA, and Champhorquinone. Composite nanofiller resin cement (AllCem Core) is as a control. Ten samples were divided into two groups. Premolar teeth were prepared with a class $V$ lift and were compressed using these two ingredients. The sample of the shear strength was tested using Universal Testing Machine (UTM). Data were analyzed by using the Independent Sample T-Test. The results showed that $60 \%$ of composite nanosisal resin cement had an average shear strength of $13.10 \mathrm{MPa}$ and $4.92 \mathrm{MPa}$ of composite nanofiller resin cement. Data analysis showed a significant difference $(p=0,000)$. The shear strength of composite nanosisal resin cement was $60 \%$ greater than that of composite nanofiller resin cement.
\end{abstract}

Keywords: Nanofiller; Nanosisal; Shear strength; Composite resin

* Corresponding author, e-mail: iqbanaditia24@gmail.com 


\section{PENDAHULUAN}

Resin komposit merupakan bahan restorasi gigi yang telah lama digunakan untuk menggantikan struktur gigi yang hilang maupun rusak dan memiliki kemampuan dapat menghasilkan warna serta kontur gigi yang baik sehingga meningkatkan faktor estetik dalam hal restorasi. ${ }^{1}$ Resin komposit terdiri atas matriks, filler (bahan pengisi) anorganik dan coupling agent. Selain ketiga komponen tersebut, terdapat komponen tambahan yaitu aktivator, pigmen, inisiator dan ultraviolet absorben. ${ }^{2}$ Resin komposit dengan filler memiliki kekuatan mekanis yang jauh lebih baik daripada resin komposit tanpa filler. $^{3}$ Semakin besar volume filler yang digunakan pada resin komposit maka semakin besar pula kekuatan mekanisnya. ${ }^{4}$

Filler yang digunakan untuk komposit berasal dari material glass. Material glass adalah bahan yang kuat, keras dan stabil dalam lingkungan. Material glass ini diformulasikan agar memiliki sifat kekerasan, kekuatan dan sifat kimiawi yang memadai sebagai filler komposit. ${ }^{5}$ Glass filler yang paling sering dipakai adalah barium glass. ${ }^{2}$ Material glass silica yang merupakan komponen utama dalam resin komposit ternyata mempunyai beberapa kelemahan yaitu, proses pengolahan yang bersifat polutan, tidak dapat diperbarui dan konsumsi energi yang tinggi sehingga diikuti oleh konsumsi bahan bakar fosil yang tinggi pula. Selain itu, proses produksi glass silica bersifat abrasif sehingga tidak baik bagi kesehatan dan lingkungan. ${ }^{6}$ Oleh karena itu, untuk menghilangkan segala macam kelemahan dari glass silica maka diperlukan filler pengganti yang ramah lingkungan dan tidak membahayakan bagi kesehatan salah satunya adalah serat alami (natural fiber).

Salah satu serat alam yang dapat dikembangkan adalah serat sisal (Agave sisalana), namun penggunaannya masih terbatas pada bidang kelautan dan pertanian. Penggunaan serat sisal ini antara lain digunakan sebagai tali, benang, karpet, dan kerajinan karena kekuatannya yang baik dan tahan lama. Serat sisal adalah suatu serat keras yang berasal dari proses ekstraksi daun tanaman sisal (Agave sisalana) yang memiliki densitas yang rendah, kekuatan spesifik dan modulusnya yang tinggi, tanpa risiko kesehatan, serta tersedia melimpah dan merupakan bahan alam terbarukan. Di India, sisal tumbuh liar sebagai pagar dan terdapat di sepanjang rel kereta api. Setiap tahunnya, produksi sisal mencapai hampir 4,5 juta ton tiap tahunnya. ${ }^{7}$ Serat sisal dipilih karena jumlahnya banyak, konsumsi energi yang rendah, lebih ramah lingkungan karena mampu terdegradasi secara alami, harganya pun lebih murah dibandingkan glass silica. ${ }^{8}$

\section{MATERIAL DAN METODE}

Penelitian ini merupakan penelitian eksperimental laboratoris murni dan dilaksanakan di ruang Skills Lab Program Studi Kedokteran Gigi UMY, Laboratorium Mikrobiologi UMY, dan Laboratorium Bahan Teknik Jurusan Teknik Mesin Sekolah Vokasi UGM Yogyakarta. Jenis sampel yang digunakan pada penelitian ini adalah semen resin nanosisal komposit $60 \%$ dan semen resin nanofiller komposit (AllCem Core). Cetakan logam berukuran $2 \mathrm{~cm}$ x $2 \mathrm{~cm}$ x 2 $\mathrm{cm}$ yang digunakan sebagai pegangan gigi saat dilakukan uji geser dan cetakan fiberglass bentuk kerucut terbalik (diameter atas $=5 \mathrm{~mm}$, diameter bawah $2 \mathrm{~mm}$, dan tinggi $=3 \mathrm{~mm}$ ) untuk penempatan semen resin.

Pembuatan nanosisal dilakukan dengan cara serat sisal dipotong dengan gunting sampai ukuran panjang helaian 5 $\mathrm{cm}$ dan ditimbang seberat 3 gram. Setelah itu langkah pertama yang dilakukan adalah scouring, serat direndam dalam larutan $\mathrm{NaOH}$ sebanyak 15 gram yang dilarutkan dalam $250 \mathrm{ml}$ air pada suhu $80^{\circ} \mathrm{C}$ selama dua jam sambil diaduk dengan magnetic stirrer. Perlakuan ini dilakukan tiga kali untuk membersihkan dari kotoran atau kandungan selain selulosa dalam serat sisal. Selanjutnya, serat disaring dan dicuci 
menggunakan aquades hingga $\mathrm{pH}$ menjadi netral. Serat sisal kemudian dikeringkan dengan hair dryer sampai kering dan disimpan.

Langkah kedua adalah serat dilakukan bleaching untuk membuat ruang diantara selulosa sehingga mudah untuk dipisahkan mikrofibrilnya. $\mathrm{NaOH}$ sebanyak 2,5 gram dilarutkan dalam $50 \mathrm{ml}$ aquades dan ditambahkan larutan $\mathrm{H}_{2} \mathrm{O}_{2} \quad 50 \%$ sebanyak $25 \mathrm{ml}$ kemudian dikocok dan ditambahkan aquades hingga keseluruhan campuran larutan mencapai $250 \mathrm{ml}$. Proses bleaching dilakukan pada suhu $80^{\circ} \mathrm{C}$ selama dua jam dan diaduk dengan magnetic stirrer dan diulang sebanyak empat kali. Setiap tahap bleaching selesai, serat disaring dan dicuci dengan aquades. Selanjutnya, serat dikeringkan menggunakan hair dryer.

Serat yang telah kering tersebut kemudian dihaluskan dengan grinder. Hidrolisis asam pada serat yang sudah halus dilakukan pada suhu $50^{\circ} \mathrm{C}$ selama 50 menit dengan menggunakan $65 \mathrm{wt} \%$ sulphuric acid sambil diaduk dengan magnetic stirrer. Kandungan serat yang dihasilkan selama proses kimiawi tersebut sekitar 5-6 wt\%. Suspensi dicairkan dengan balok es untuk menghentikan reaksi. Kemudian dilakukan pencucian dengan menggunakan centrifuge pada suhu $10^{\circ} \mathrm{C}$ dengan kecepatan 5000 rpm selama 30 menit. Dialisis terhadap aquades dilakukan untuk menghilangkan asam bebas pada dispersi. Dispersi nano-whisker yang sempurna didapatkan dengan tahap sonifikasi. Dispersi di saring dengan fritted glass filter nomor 1 untuk menghilangkan sisa agregat, dan selanjutnya adalah tahap freeze-dried. Tahap freeze-dried menggunakan Freeze dryer sehingga didapatkan nanosisal dalam bentuk serbuk semi padat.

Persiapan sampel dilakukan dengan menyiapkan alat dan bahan serta pengumpulan gigi yang akan digunakan sebagai sampel. Sampel yang digunakan pada penelitian ini adalah gigi premolar

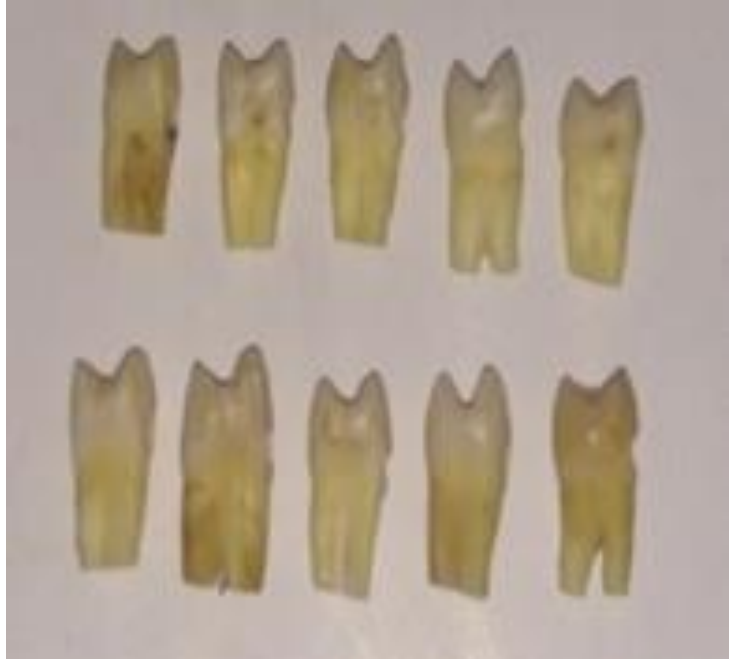

Gambar 1. Gigi Premolar

post ekstraksi bebas karies sebanyak 10 gigi, yang akan dibagi menjadi dua kelompok dan tiap kelompok terdiri dari 5 gigi. Gigi premolar dipreparasi kelas $\mathrm{V}$ sampai kedalaman dentin. Preparasi dilakukan dengan menggunakan round bur dan inverted bur. Serbuk akrilik dicampurkan dengan cairannya dan diaduk merata. Selanjutnya, adonan resin akrilik dimasukkan kedalam cetakan logam sampai penuh, kemudian gigi premolar yang telah dipreparasi ditanam ke dalam cetakan yang telah berisi resin akrilik tersebut secara perlahan. Setelah resin akrilik kering, cetakan dilepas.

Pembuatan sampel dilakukan dengan cara nanosisal semi padat ditimbang dengan timbangan digital seberat 0,003 gram $(60 \%)$ dan dicampur dengan 0,5 gram Bis-GMA, 0,02 ml TEGDMA, 0,02 gram UDMA, 0,09 gram champorquinon.. Setelah pencampuran dengan bahan tersebut, diperoleh adonan semen resin nanosisal komposit.

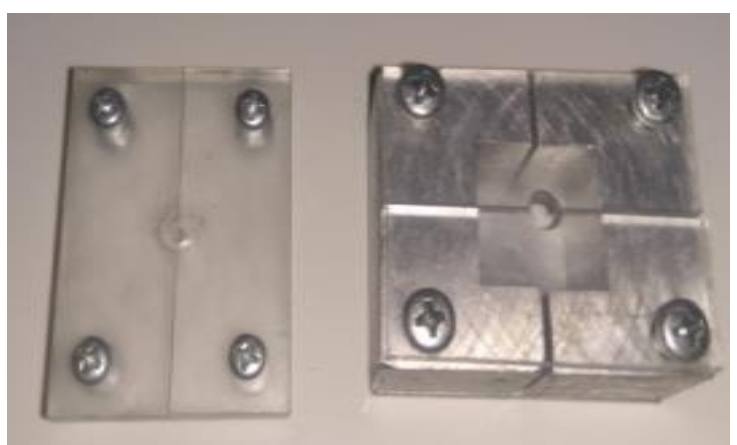

Gambar 2. Cetakan fiberglass dan cetakan logam 
Gigi yang telah dipreparasi dibersihkan dengan cavity cleanser, selanjutnya diberi perlakuan pengolesan bahan etsa (asam fosfat 37\%) sebanyak 1 kali oles menggunakan microbrush selama 15 detik. Spesimen dicuci menggunakan three-way syringe secara perlahan selama 20 detik dan diangin-anginkan dengan menggunakan three-way syringe dan jangan sampai terlalu kering (moist).

Bahan bonding dioleskan pada permukaan spesimen yang teretsa sebanyak 1 kali oles selama 10 detik menggunakan microbrush, setelah itu diangin-anginkan, kemudian disinar menggunakan visible light cure tegak lurus bidang preparasi selama 20 detik. Sampel ditumpat dengan bahan semen resin komposit nanosisal dan disinar dengan visible light cure selama 40 detik dengan jarak selapis pita seluloid. Hasil ini disebut sebagai kelompok A.

Semen resin nanofiller komposit sintetis diambil dari tube dengan menggunakan plastis instrument. Gigi yang telah dipreparasi dibersihkan dengan cavity cleanser, selanjutnya diberikan perlakuan pengolesan bahan etsa (asam fosfat 37\%) sebanyak 1 kali oles menggunakan microbrush selama 15 detik. Spesimen dicuci menggunakan three-way syringe secara perlahan selama 20 detik dan diangin-anginkan dengan menggunakan three-way syringe jangan sampai terlalu kering (moist).

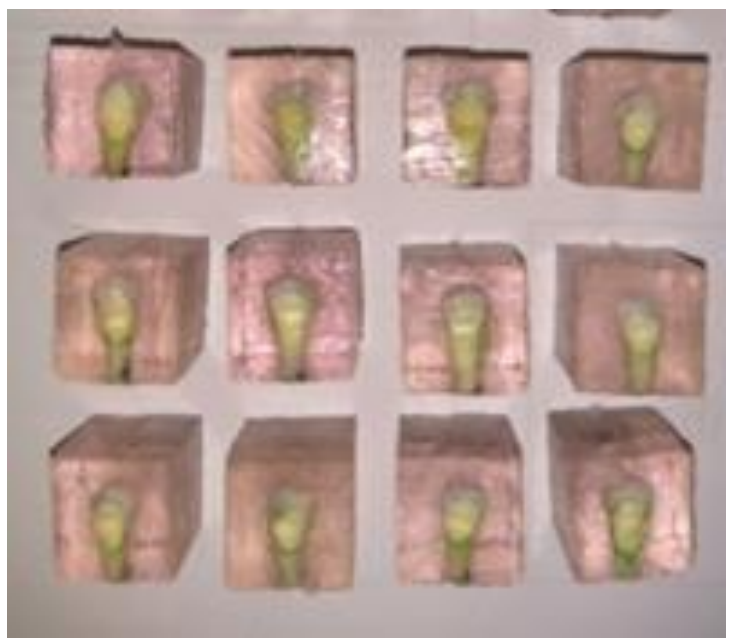

Gambar 3. Gigi premolar setelah ditanam di resin

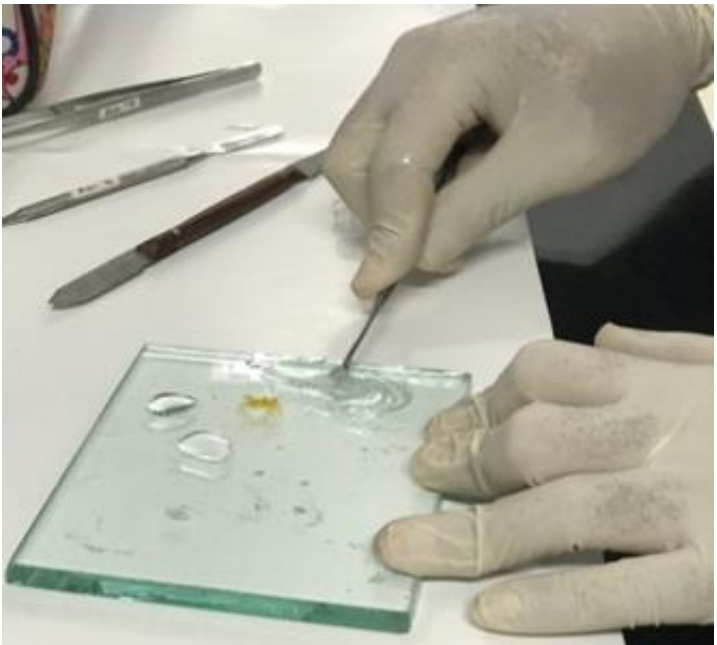

Gambar 4. Pencampuran bahan pembuatan semen resin nanosisal

Bahan bonding dioleskan pada permukaan spesimen yang teretsa sebanyak 1 kali oles selama 10 detik menggunaan microbrush, setelah itu diangin-anginkan, kemudian disinar menggunakan visible light cure tegak lurus bidang preparasi selama 20 detik. Sampel ditumpat dengan bahan semen resin komposit nanofiller dan disinar dengan visible light cure selama 40 detik dengan jarak selapis pita seluloid. Hasil ini disebut sebagai kelompok B.

Uji Kekuatan Geser antara kelompok A dan B dilakukan dengan menggunakan Universal Testing Machine (Pearson Pake, London) dengan meletakkan subjek penelitian pada meja sampel dan difiksasi, Di atas meja terdapat beban telah terfiksasi.

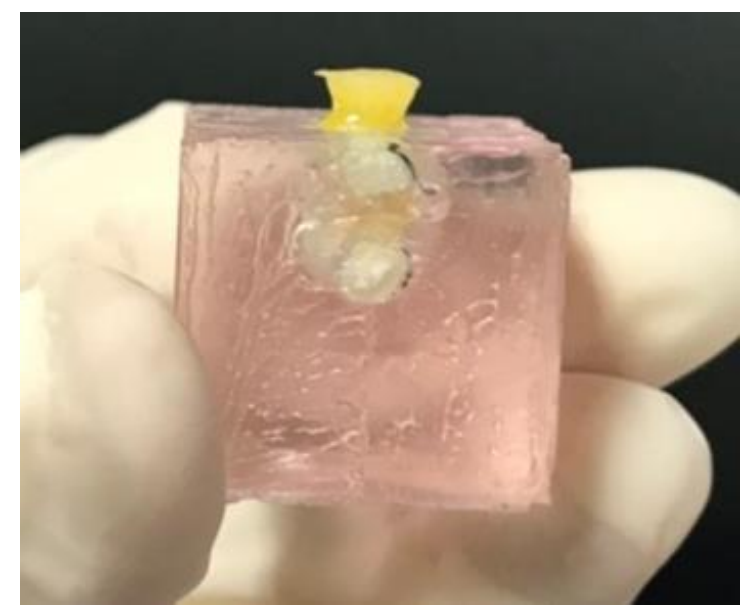

Gambar 5. Pengaplikasian semen resin pada permukaan gigi 


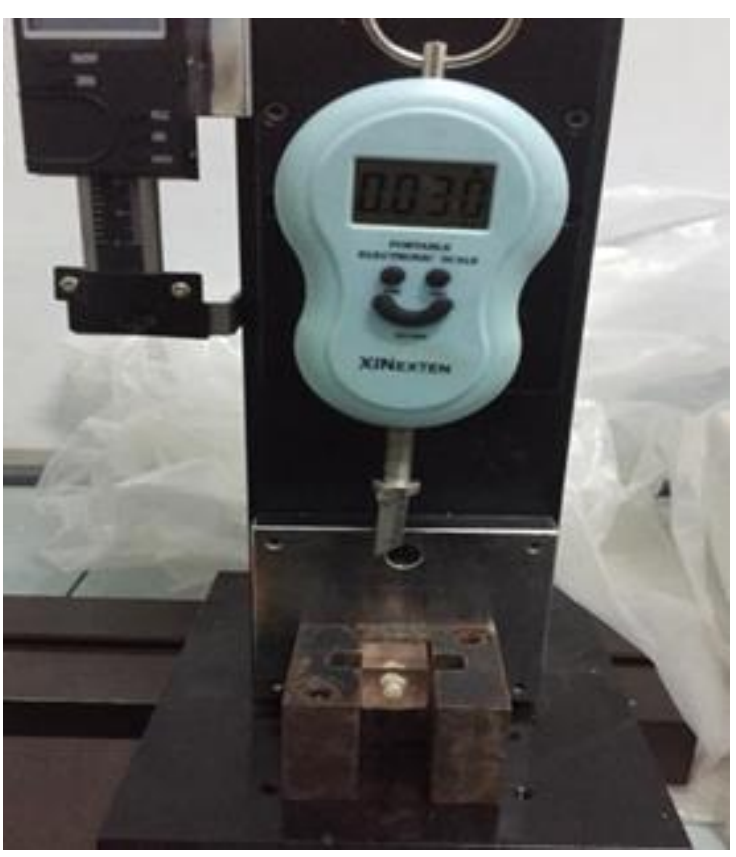

Gambar 6. Pengukuran kekuatan geser menggunakan Universal Testing Machine

Kemudian mesin dinyalakan sehingga beban tersebut akan bergerak turun hingga menggeser resin komposit dengan kecepatan geser $0,5 \mathrm{~mm} /$ menit dan beban $2 \mathrm{kN}$ berdasarkan ketentuan ISO TR 1140521 dan ISO 4049 standards. Data yang didapatkan berupa satuan $\mathrm{N}$ kemudian dirubah kedalam MPa dengan rumus :

$$
\begin{aligned}
& \text { Kekuatan Geser }(\tau)=F / \\
& \pi r^{2}
\end{aligned}
$$

Keterangan :

$\mathrm{F}$ = besarnya kekuatan yang diaplikasikan pada specimen $(\mathrm{N})$

$\pi=3,14 ; 22 / 7$

$\mathrm{r}=$ jari-jari lingkaran pada spesimen $(\mathrm{mm})$

\section{HASIL}

Berikut hasil dari uji kekuatan tekan dari masing-masing sampel. Tabel 1 menunjukkan nilai rata-rata dan hasil pengukuran kekuatan geser dengan satuan MPa dari masing-masing sampel uji. Hasil tersebut menunjukkan nilai kekuatan tertinggi untuk semen resin nanosisal komposit $60 \%$ adalah 13,10 Mpa dan semen resin nanofiller komposit adalah 4,92 Mpa. Selanjutnya data dari nilai kekuatan geser tersebut dilakukan uji normalitas menggunakan uji Saphiro-Wilk (sampel < 50).
Tabel 1. Hasil uji kekuatan geser resin komposit dalam MPa

\begin{tabular}{|c|c|c|}
\hline & \multicolumn{2}{|c|}{ Kekuatan Geser (MPa) } \\
\hline & Semen Resin & Semen Resin \\
\hline & Nanosisal & Nanofiller \\
\hline & Komposit $60 \%$ & komposit \\
\hline & (Kelompok A) & (Kelompok B) \\
\hline 1 & 10,23 & 4,92 \\
\hline 2 & 13,10 & 4,06 \\
\hline 3 & 12,92 & 3,70 \\
\hline 4 & 8,47 & 3,30 \\
\hline 5 & 10,59 & 1,90 \\
\hline Mean & 11,07 & 3,58 \\
\hline Std. Deviasi & 1,95 & 1,11 \\
\hline
\end{tabular}

Hasil perhitungan uji normalitas data pada Tabel 2 menunjukkan bahwa distribusi data tiap kelompok perlakuan adalah normal dikarenakan nilai signifikansi atau $\mathrm{p}>0,05$. Setelah itu, data dilakukan uji homogenitas untuk mengetahui variansi datanya. Hasil dari uji homogenitas pada Tabel 3 didapatkan nilai signifikansi atau $\mathrm{p}>0,05$ menunjukkan data yang didapatkan memiliki variansi yang sama. Setelah dilakukan uji normalitas diketahui bahwa sebaran data normal dan variansi data sama maka uji selanjutnya yang dapat dilakukan yaitu uji statistic parametrik independent sample $t$ Test.

Data yang didapatkan dari uji independent sample t-Test tersebut menunjukkan nilai signifikansi atau $\mathrm{p}=$ $0,000(\mathrm{p}<0,05)$ yang memiliki arti bahwa data kekuatan geser antara bahan semen resin nanosisal komposit $60 \%$ dan semen resin nanofiller komposit memiliki perbedaan yang bermakna.

Tabel 1. Uji Normalitas Kekuatan Geser

\begin{tabular}{lccc}
\hline Kelompok & \multicolumn{3}{c}{ Shapiro Wilk } \\
& Statistik & Df & Sig. \\
\hline Nanosisal &, 911 & 5 &, 475 \\
$60 \%$ &, 971 & 5 &, 883 \\
Nanofiller &, 971 \\
\hline
\end{tabular}

Tabel 2. Hasil Uji Homogenitas dengan Levene Test

\begin{tabular}{cccc}
\hline $\begin{array}{c}\text { Levene } \\
\text { Statistic }\end{array}$ & $\mathrm{df} 1$ & $\mathrm{df} 2$ & Sig. \\
\hline 2,424 & 1 & 8 &, 158 \\
\hline
\end{tabular}




\section{PEMBAHASAN}

Sampel dengan semen resin nanosisal komposit $60 \%$ memiliki kekuatan geser yang lebih besar dibandingkan dengan sampel semen resin nanofiller komposit. Dari hasil uji kekuatan geser didapatkan rata-rata kekuatan geser semen resin nanosisal komposit $60 \%$ sebesar 11,07 Mpa sedangkan pada semen resin nanofiller komposit sebesar 3,58 Mpa.

Hal yang dapat mempengaruhi kekuatan geser dari suatu bahan adalah karena perlekatan dari bahan tersebut kurang baik. Perlekatan yang kurang baik dapat disebabkan karena adanya kebocoran mikro pada interface bonding. Kebocoran mikro ini biasanya disebabkan karena shrinkage polimerisasi komposit, perlekatan dan pembasahan yang buruk, stres termal, dan beban mekanis. Proses polimerisasi yang menghasilkan shrinkage menyebabkan timbulnya stress yang dapat melebihi kekuatan ikatan disekitar gigi, hal ini dapat mengakibatkan kegagalan perlekatan antar permukaan (interface bonding) antara permukaan gigi dengan bahan komposit sehingga dapat menyebabkan terjadinya kebocoran mikro. Resin komposit yang mengalami shrinkage selama polimerisasi akan menghasilkan kekuatan yang berbeda dengan kekuatan perlekatan, sehingga dapat mengganggu perlekatan terhadap permukaan gigi yang berdampak pada menurunnya kekuatan geser. $^{9}$

Semen resin nanosisal komposit dapat mengurangi terjadinya shrinkage saat polimerisasi, selain itu komposit dengan tambahan bahan serat alami sebagai filler juga memiliki keuntungan yaitu dapat meningkatkan sifat mekanis, meningkatkan resistensi terhadap panas, mengurangi thermal expansion, dan mengurangi creep. ${ }^{10}$ Semen resin komposit nanosisal mengandung volume filler sebesar $60 \%$ sedangkan pada semen resin komposit nanofiller (AllCem Core) mengandung volume filler sebesar $70 \%$. Ilie \& Hickel (2011), ${ }^{14}$ mengemukakan bahwa volume filler pada resin komposit bila lebih dari
$60 \%$ akan mengakibatkan kerusakan yang lebih tinggi, dan menyebabkan penurunan sifat mekanik. Hal inilah yang mungkin mempengaruhi kekuatan geser dari semen resin komposit itu sendiri.

BIS-GMA pada resin komposit memiliki viskositas yang lebih tinggi sehingga harus memerlukan bahan tambahan untuk mengencerkannya. Bahan tersebut berupa monomer lain yang kekentalannya lebih rendah (berat molekul rendah), seperti trietilenglikol dimetakrilat (TEGDMA). ${ }^{3}$ Akan tetapi, apabila kandungan TEGDMA didalam semen resin komposit nanofiller berlebihan atau tidak seimbang, maka dapat menyebabkan peningkatkan polimerisasi shrinkage yang berdampak terjadinya kebocoran mikro antara permukaan gigi dengan resin komposit pada saat polimerisasi. ${ }^{9}$ Semen resin nanosisal komposit mengandung UDMA di dalamnya sedangkan pada semen resin nanofiller komposit tidak ada kandungan UDMA. UDMA dapat membentuk polimer cross-link yang padat sehingga dapat meningkatkan kekuatan mekanis. Pada saat polimerisasi bahan tersebut akan meregang atau tertarik sehingga dapat mencegah rantai individual bergeser satu sama lain dan apabila stress akibat polimerisasi hilang, rantai polimer cross link dapat kembali ke posisi awal dan objek kembali kebentuk semula. UDMA memiliki berat molekul yang lebih tinggi sehingga dapat meningkatkan derajat polimerisasi. ${ }^{11}$

Mekanisme adhesi antara bonding dengan gigi dimulai pada saat melakukan pengetsaan dengan menggunakan asam fosfat pada email yang nantinya akan menghasilkan energi permukaan yang tinggi pada permukaan email sehingga menyebabkan demineralisasi mineral penyusun pada email. Energi permukaan yang tinggi ini akan meningkatkan efisiensi wetting (pembasahan) oleh resin yang bersifat hidrofobik sehingga akan memperluas dan memperkuat bidang ikatan (interface bonding). Pada prinsipnya pengetsaan dentin akan melarutkan smear 
layer pada permukaan dentin dan mendemineralisasi dentin yang akan mengakibatkan terbukanya mikropit. ${ }^{12}$

Nanosisal dan polimer epoksi juga merupakan bahan organik, sehingga kedua material ini dapat berikatan dengan baik. Jenis ikatan yang dapat terjadi pada interface bonding polimer epoksi dan serat alami terdiri dari mechanical bonding yang merupakan mekanisme ikatan yang saling mengunci terjadi pada dua permukaan yaitu resin dan serat yang kasar namun beban harus paralel terhadap interface. Electrostatic Bonding terjadi karena adanya gaya tarik antara dua permukaan yang berbeda muatan listrik dalam skala atomik. Tetapi ikatan ini akan sempurna bila tidak adanya gas pada permukaan serat. Chemical bonding merupakan ikatan yang terjadi akibat adanya energi yang lebih bersifat kimia, ikatan ini diperoleh dari sekumpulan ikatan kimia yang berperan pada luas penampang serat sesuai jenis ikatan kimia yang ada pada serat maupun resin. ${ }^{13}$

Semen resin Allcem Core memiliki kandungan filler yang lebih tinggi dibandingkan dengan jenis semen resin lain dengan merek yang berbeda. ${ }^{15}$ Kandungan filler pada semen resin akan memberikan pengaruh terhadap kekuatan mekanis dari semen resin komposit. Semakin tinggi volume filler pada resin komposit maka akan semakin tinggi pula tingkat porusitasnya yang berpengaruh pada menurunnya kekuatan geser. ${ }^{16}$ Hal inilah yang dapat menyebabkan nilai dari kekuatan geser semen resin nanofiller komposit lebih rendah dibandingkan dengan semen resin nanosisal komposit.

Hasil rata-rata kekuatan geser dari semen resin nanosisal komposit $60 \%$ yang didapatkan pada penelitian ini yaitu 11,07 MPa yang berarti memerlukan gaya geser sebesar 11,07 $\mathrm{N}$ untuk setiap $\mathrm{mm}^{2}$ bahan semen resin nanosisal komposit $60 \%$ yang diaplikasikan pada gigi agar bahan tersebut lepas ikatannya dengan gigi. Sedangakan hasil rata-rata kekuatan geser dari semen resin nanofiller komposit yang didapatkan pada penelitian ini yaitu 3,58 $\mathrm{MPa}$ yang berarti memerlukan gaya geser sebesar 3,58 $\mathrm{N}$ untuk setiap $\mathrm{mm}^{2}$ bahan semen resin nanofiller komposit yang diaplikasikan pada gigi agar bahan tersebut lepas ikatannya dengan gigi.

\section{KESIMPULAN}

Terdapat perbedaan kekuatan geser antara semen resin nanosisal komposit $60 \%$ dan semen resin nanofiller komposit (AllCem Core, FGM). Semen resin nanosisal komposit $60 \%$ menghasilkan kekuatan geser lebih kuat dibandingkan dengan semen resin nanofiller komposit (AllCem Core, FGM).

\section{DAFTAR PUSTAKA}

1. Powers JM, Sakaguchi RL. Craig's Restorative Dental Materials. Philadelphia: Elsevier Mosby; 2012.

2. Anusavice KJ. Buku Ajar Ilmu Bahan Kedokteran Gigi (L. Juwono, Trans.) (Edisi 10). Jakarta: Penerbit Buku Kedokteran EGC; 2004.

3. O'Brien WJ. Dental Materials and Their Selection (third ed.). Chicago: Quintessence Publishing Co; 2002.

4. Thomaidis, S., Kakaboura, A., Mueller, W. D., \& Zinelis, S. Mechanical properties of contemporary composite resins and their interrelations. Dent. Mater. J. 2013; 29(8): e132-e141.

5. Gladwyn M, Bagby M. Clinical Aspects of Dental Materials : Theory, Practice, and Cases (3rd ed.). Philadelphia: Lippincott Williams \& Wilkins; 2009.

6. Joshi, S. V., Drzal, L. T., Mohanty, A. K., \& Arora, S. Are natural fiber composites environmentally superior to glass fiber reinforced composites?. Composites Part A: Applied science and manufacturing. 2004; 35(3): 371376.

7. Kusumastuti, A. Aplikasi serat sisal sebagai komposit polimer. Jurnal Kompetensi Teknik. 2009; 1(1): 27-32.

8. Munandar, I., \& Savetlana, S. 
Kekuatan Tarik Serat Ijuk (Arenga Pinnata Merr). Jurnal Ilmiah Teknik Mesin. 2013; 1(3): 52-58.

9. Garg N, Garg A. Textbook of operative dentistry. 1st ed. New Delhi: Jaypee Brothers Medical Publishers; 2010.

10. Kaczmar, J. W., Pach, J., \& Kozlowski, $R$. Use of natural fibres as fillers for polymer composites. Int. Polym. Sci. Technol. 2007; 34(6): 45-50.

11. Papakonstantinou, A. E., Eliades, T., Cellesi, F., Watts, D. C., \& Silikas, N. Evaluation of UDMA's potential as a substitute for Bis-GMA in orthodontic adhesives. Dent. Mater. J. 2013; 29(8): 898-905.

12. Van Meerbeek, B., De Munck, J., Yoshida, Y., Inoue, S., Vargas, M., Vijay, P., ... \& Vanherle, G. Adhesion to enamel and dentin: current status and future challenges. Oper. Dent. 2003; 28(3): 215-235.
13. Betan, A. D., Soenoko, R., \& As, A. Pengaruh persentase alkali pada serat pangkal pelepah daun pinang (Areca Catechu) terhadap sifat mekanis komposit polimer. Jurnal Rekayasa Mesin. 2014; 5(2): 119-126.

14. Ilie, N., \& Hickel, R. Resin composite restorative materials. Aust. Dent. J. 2011; 56: 59-66.

15. Onay, E. O., Korkmaz, Y., \& Kiremitci, A. Effect of adhesive system type and root region on the push-out bond strength of glass-fibre posts to radicular dentine. Int. Endod. J. 2010; 43(4): 259-268.

16. Pickering, K. L., Efendy, M. A., \& Le, T. M. A review of recent developments in natural fibre composites and their mechanical performance. Compos. Part A Appl. Sci. Manuf. 2016; 83: 98-112. 